\title{
El giro creativo en el trabajo contemporáneo: una mirada crítica desde las condiciones laborales del campo cultural de Santiago de Chile ${ }^{1}$
}

Creative turn in contemporary work: a critical analysis from Santiago de

Chile cultural labor working conditions

\author{
Carla Pinochet Cobos \\ Universidad Alberto Hurtado, Chile \\ Constanza Tobar Tapia \\ Universidad de Chile, Chile
}

\begin{abstract}
RESUMEN Este artículo explora los fundamentos del giro creativo en el trabajo contemporáneo, analizando las razones que han ido posicionando a los productores culturales - trabajadores de los mundos del arte, los sectores creativos y el campo intelectual- como referentes para otros sectores productivos, en el marco de las transformaciones del capitalismo flexible. Como contraparte de estos discursos celebratorios, y en base a una estrategia metodológica cualitativa que permitió registrar las prácticas y discursos del medio creativo de Santiago de Chile, ahondaremos en el reverso del modo de vida artístico: las precarias condiciones laborales y los invisibilizados costos subjetivos que enfrentan quienes se desenvuelven en dichas escenas. En base a este levantamiento empírico, este texto busca contribuir a la comprensión de los procesos de construcción de subjetividad en el capitalismo tardío, examinando las singularidades de un tipo de actividad que encierra una paradoja: a la vez que se convierte en un modelo laboral de exportación hacia otros dominios, su condición productiva - esto es, en su valoración en tanto trabajo- es desconocida en diversos sentidos y niveles.
\end{abstract}

1. Artículo enmarcado en el proyecto FONDECYT de Iniciación № 11170319: "Prácticas de ocio y trabajo cognitivo: Un estudio de los sectores creativos, artísticos e intelectuales". ANID, Chile. 
PALABRAS CLAVE Trabajo artístico; creatividad; capitalismo flexible; precariedad.

ABSTRACT This article explores the foundations of the creative turn in contemporary work, analysing the reasons that have made cultural producers - workers in the art world, the creative sectors and the intellectual field - gain position as model for other productive sectors, within the framework of flexible capitalism transformations. As a counterpart to these celebratory discourses, and based on a qualitative methodological strategy that allowed us to register the practices and discourses of the creative milieu of Santiago de Chile, we will delve into the reverse side of the artistic lifestyle: the precarious working conditions and the invisible subjective costs faced by those who work in these scenes. Based on this empirical survey, this text seeks to contribute to the understanding of the processes of construction of subjectivity in late capitalism. It examines the singularities of a type of activity that contains a paradox: while it becomes a labor model to export to other domains, its productive conditions - its valuation as work - is unknown in various senses and levels.

KEY WORDS Artistic work; creativity; flexible capitalism; precarity.

\section{Introducción}

En la producción contemporánea, las formas de trabajo basadas en la creatividad han dejado de ser patrimonio exclusivo de agentes especializados (Appadurai, 2001; García Canclini, 2010), y sus dinámicas distintivas han sido progresivamente incorporadas en los más diversos sectores productivos. En este artículo, indagaremos en las razones que han puesto de relieve el modelo laboral de los artistas y agentes creativos en el contexto contemporáneo, señalando las afinidades que lo convierten en un referente idóneo para los procesos de flexibilización del capitalismo postfordista. Al mismo tiempo, en línea con la literatura internacional que ha caracterizado las diversas fuentes de precariedad que signan el trabajo en estos campos, nuestro análisis busca explorar las luces y sombras del "giro creativo" del trabajo, aproximándonos a sus contradicciones constitutivas: las de ser una actividad laboral que niega o esconde su propia naturaleza productiva. ¿Qué mecanismos hacen posible que, a pesar de las hostiles condiciones en las que se desenvuelven los productores culturales ${ }^{2}$, sus estilos laborales adquieran un estatuto ejemplar en

2. Entenderemos en este artículo el concepto de "productores culturales" de un modo amplio e inclusivo, que involucra a los trabajadores que se desempeñan en los campos artísticos, creativos e intelectuales, en tanto: a) todos ellos generan productos, ante todo, inmateriales, pues es su valor simbólico el que prevalece en desmedro de los objetos que lo portan; b) todos se desenvuelven en 
la escena contemporánea? ¿Qué perspectivas pueden desprenderse al examinar los costos subjetivos asociados a estas formas de trabajo? ¿Qué advertencias nos ofrecen las voces de quienes, aun cuando experimentan cotidianamente las dificultades y los riesgos de este modo de vida, escogen persistir en el mundo de las artes y la creatividad?

Este estudio se aproxima a estas interrogantes a partir de una estrategia metodológica cualitativa, que permitió indagar en las prácticas y discursos de los productores culturales de la ciudad de Santiago de Chile entre los años 2017 y 2019. Consideramos dentro del universo de estudio tres subcampos específicos: los artistas -incluyendo a quienes se desempeñan en producción de artes visuales, música, literatura, artes escénicas y cine-; los creativos — contemplando a profesionales del diseño, la publicidad, la ilustración, la multimedia, y la arquitectura-; y los intelectuales - abarcando a investigadores y académicos de las artes y humanidades-. Consideramos una muestra total de 64 casos, correspondientemente desagregados en términos de disciplina, género, edad y condiciones laborales, cada uno de los cuales participó mediante dos vías de recolección de información. Por una parte, se les invitó a registrar en una bitácora las actividades desarrolladas en una semana aleatoria de sus vidas, indicando dimensiones tales como el lugar, momento de día, acompañante, relación con el hacer profesional y efectos percibidos (emocionales y cognitivos) de cada actividad. El ejercicio, que apelaba a la capacidad autorreflexiva que caracteriza a estos sectores, entregó al estudio una perspectiva autoetnográfica (Blanco, 2012; Ellis y Bochner, 2000), estableciendo vínculos entre lo personal y lo cultural. Al término del registro, se realizó una entrevista en profundidad semi-estructurada con cada uno de los informantes, que buscaba indagar en sus narrativas - es decir, "el reporte 'nativo' de prácticas y valores” (Rojek, 2005) - en torno a los modos en que se construyen las fronteras entre el trabajo y ocio en sus vidas. La sistematización de las entrevistas y las bitácoras se realizó con el apoyo del software cualitativo ATLAS. ti 8 , que retoma las bases de la teoría fundada como paradigma de análisis: en base a una codificación emergente del material empírico recogido, el estudio fue desarrollando unidades conceptuales susceptibles de ser descritas en términos de sus propiedades, características y dimensiones (Strauss y Corbin, 2002).

una estructura flexible en términos de horarios y lugares de trabajo, implicando una necesidad de autoorganizar el propio tiempo y la dificultad de escindir el trabajo del domicilio; c) todos se ven en la necesidad de invertir una parte significativa de su tiempo en trabajo no remunerado, dentro del cual adquieren saberes y competencias que - aunque no se les pagan - se les exigen y se utilizan en el desempeño de su actividad profesional; y, especialmente, $\mathbf{d}$ ) todos manifiestan un alto nivel de identificación con el trabajo desempeñado, proyectando en éste una fuente prioritaria de satisfacción personal y respondiendo en mayor medida a objetivos propios que a asignaciones impuestas por sus superiores. La denominación, que no resulta posible discutir aquí con detalle, adquirirá en el texto usos alternativos - trabajadores culturales, sectores creativos, agentes creativos, etc.que se plantean como indistintos, es decir, no buscan marcar recortes específicos de la muestra. 
El recorrido a continuación busca ofrecer elementos conceptuales y empíricos para comprender, en base a la experiencia de los productores culturales que participaron de este estudio, el vínculo dispar que la labor creativa establece con el capitalismo flexible, por una parte, y con la propia noción de trabajo, por la otra. Iniciaremos documentando algunas aproximaciones que han intentado explicar, desde posturas diversas, el engarce contemporáneo entre el modo de vida artístico y los nuevos imperativos del trabajo flexible. Posteriormente, caracterizaremos los rasgos que el modelo laboral del capitalismo tardío ha seleccionado de la práctica creativa, explorando los efectos no deseados de este giro creativo del trabajo en base a dos ejes: el estilo de vida artístico como insumo para ciudades y economías creativas, y la pasión creativa como fuente de vulnerabilidades laborales en el régimen neoliberal. Luego abordaremos, con un importante énfasis en lo empírico, los costos subjetivos del trabajo creativo. Para ello, organizaremos las tensiones constitutivas de estas actividades laborales en torno a tres elementos, en los que la condición productiva se pone en entredicho: el tiempo, el dinero, y la gestión. En base a ese levantamiento, delinearemos las tácticas y estrategias que despliegan nuestros informantes para navegar la precariedad inherente a estos campos, para finalmente reflexionar acerca de los modos que encuentran los propios actores para significar su propia producción y, en el mismo gesto, desmarcarse de la esfera del trabajo.

\section{Trabajo creativo y capitalismo postfordista: afinidades basales}

Aunque históricamente el arte y el trabajo han tendido a presentarse como conceptos divergentes y hasta contradictorios, las transformaciones laborales experimentadas en las últimas décadas a escala global han activado vínculos inéditos entre ambos. Como ha sido vastamente documentado por diversos autores, junto al desplazamiento del modelo capitalista hacia una producción racionalizada y su consecuente quiebre con la estructura salarial del trabajo (Castel, 1997; De Mattos, 1992; Rifkin, 1997), tuvo lugar una significativa reorganización de sus lógicas internas que modificó el ethos del trabajo. Se produjo, así, una "ampliación del sujeto laboral" (De la Garza, 2005): los trabajadores, en el escenario del capitalismo postindustrial, deben enfrentar condiciones de empleo cada vez más móviles, flexibles e inciertas (Castel, 2004; Sennett, 2001). Es en este marco que el trabajo artístico comienza a presentarse como un refuerzo positivo para diversos sectores productivos en los que, tradicionalmente, la creatividad solía ser un estorbo antes que una virtud.

La afinidad entre trabajo creativo y flexibilización laboral ha sido problematizada desde distintos ángulos. Tal vez su desarrollo conceptual más reconocido es el que ofrecen Boltanski y Chiapello (2002), quienes observan el proceso mediante el cual el estilo de vida de los artistas ha sido adoptado como modelo para amplios sectores de los trabajadores contemporáneos. Los autores describen cómo el "nuevo espíritu del 
capitalismo" ha incorporado en sus propios términos una de las fuentes de indignación hacia el deshumanizado trabajo industrial: la llamada «crítica artista». Agrupando valores diversos que han sido atribuidos a estos sectores - libertad, autonomía, singularidad, creatividad, autenticidad -, la crítica artista habría sido absorbida por el modelo laboral emergente, en desmedro de la otra fuente de cuestionamientos que identifican los autores: la crítica social, basada en la solidaridad, la justicia, la fraternidad y la dignidad. De este modo, el postfordismo opera en el mundo del trabajo a través de una doble operación: así como introduce nuevas posibilidades expresivas y de autorrealización personal -inspiradas en el mundo artístico- para los sujetos, a la vez desarticula las condiciones contractuales, temporales y espaciales que circunscribían el trabajo moderno. Proliferan, entonces, las prácticas laborales flexibles. Los supuestos agentes libres que habría de producir el nuevo modelo logran eximirse de las obligaciones de la oficina y de las rutinas esclavizantes, pero también de toda garantía social y de la regularidad de un salario.

Otras aproximaciones comparten el sentido de urgencia que los cruces entre trabajo artístico y capitalismo flexible cobran en la actualidad, pero se distancian del imaginario con el que Boltanski y Chiapello retratan a una clase creativa ${ }^{3}$ privilegiada, elitista y homogénea, así como del lugar fundante que le otorgan en la emergencia del nuevo modelo. En un texto que discute las "desdichas de la crítica artista", Lazzarato (2007) contradice la genealogía que dichos autores franceses trazan entre el ideario de la libertad y el trabajo de los artistas. Este último no sería el inspirador del régimen laboral contemporáneo, sino un ámbito donde su lógica - la del "capital humano avanzado" - ha sido también impuesta. Esta racionalidad dictamina que los trabajadores deben gestionar por cuenta propia, bajo criterios de costo/inversión y de acuerdo a la ley de la oferta y la demanda, todos los aspectos involucrados en el desarrollo de su vida laboral: "la formación, el crecimiento, la acumulación, la mejora y la valorización «de sí» en tanto que «capital», a través de la gestión de todas sus relaciones, sus elecciones y sus conductas" (2007, s/n). El paradigma del "empresario de sí mismo" que caracteriza al capitalismo tardío opera sobre los trabajadores - y entre ellos, los artistas- desdoblando en una misma figura dos funciones que solían aparecer de forma separada: la de la subjetivación y la de la explotación. El trabajador deviene, por tanto, simultáneamente en "patrón de sí mismo y esclavo de sí mismo, capitalista y proletario, sujeto de enunciación y sujeto de enunciado" (Lazzarato, 2007, s/n).

3. Sin ánimos de eludir la discusión que puede propiciarse en torno a esta categoría, el uso del concepto de "clase creativa" en el presente escrito no adscribe necesariamente a las implicaciones teóricas que conlleva en sus desarrollos más populares; específicamente, en el trabajo de Richard Florida. 
Sea o no el germen de los modos de subjetivación del capitalismo flexible, el trabajo artístico presenta algunas singularidades que lo amarran estrechamente a este modelo laboral, convirtiéndolo en un sector ejemplar para el conjunto del mundo productivo. En primer lugar, esta inédita visibilidad de la labor creativa tiene lugar en el marco de un auge del trabajo inmaterial: a partir de los años noventa, se configuró una economía globalizada y deslocalizada - la denominada "Nueva Economía" - en la que "la gente trabaja con su cerebro en vez de con sus manos" (New Economy Encyclopedia, 1997). Para el creciente "cognitariado" (Berardi, 2003) que engrosa las filas del capitalismo cognitivo ${ }^{4}$, la fábrica está en todas partes, erosionando las fronteras entre espacio de trabajo y domicilio; tiempo de trabajo y tiempo libre; trabajo remunerado y no remunerado (Yáñez, 2001). Como bien saben los artistas desde hace mucho tiempo atrás, en el mundo laboral postfordista la diferencia cualitativa entre «trabajo» $\mathrm{y}$ «no trabajo» disminuye, y el límite entre ambas es "arbitrario, mutable, sujeto a decisión política” (Virno, 2008, p. 115). Las prácticas laborales contemporáneas resultan, en estos sentidos, altamente consistentes con el trabajo - flexible, ubicuo, inmaterial- de los artistas y creativos.

Por otra parte, tal como han apuntado diversos autores, se despliega en estos sectores una contradicción basal: aunque las clases creativas enfrentan una precarización masiva de sus condiciones de trabajo, a la vez eligen su ocupación y la perciben en base a una idea de soberanía, infundida por la realización de sí y la autonomía (Lorey, 2006). De este modo, el discurso social que pone la creatividad en su centro (Raunig, Ray y Wuggenig, et al., 2011) poseería una doble función de refuerzo para el sistema hegemónico: por una parte, el fomento del trabajo creativo suprime "toda connotación política de la esfera laboral", reemplazándola por "la gratificación de las propias aspiraciones y expectativas, y por la expresión de uno mismo" (Mc Robbie, 2010, p. 155); y, por la otra, plantea estas condiciones como socialmente deseables, proveyendo de todo un modelo de vida laboral para el resto de la población (Mc Robbie, 2007).

4. El llamado capitalismo cognitivo (Moulier Boutang 2007; VVAA 2004) descansa en una nueva interdependencia entre la producción de valor económico y la producción de conocimiento, cuya existencia depende de un conjunto de disposiciones sistémicas estructurales orientadas a la privatización del saber (Ossa, 2016). Es importante destacar que el conocimiento, en tanto motor económico, pone en crisis la teoría del valor, tanto en sus expresiones marxistas como en su filosofía liberal: ya que la creatividad no es un bien escaso - y por tanto, un bien económico-, su valor de cambio está vinculado directamente con la "capacidad práctica de limitar su difusión libre", ya sea por medios jurídicos (como los derechos de autor, licencias y patentes) o monopólicos (Corsani 2000). 
Así, tras haber constituido históricamente un dominio profesional marginal en el mundo productivo, el trabajo artístico y creativo adquiere en la era postfordista un status protagónico, en tanto sus modos de hacer engarzan con el nuevo espíritu del capitalismo: flexible, autodirigido, compatible con (y acostumbrado al) empleo precario, y orientado a la producción de éxitos profesionales (Ross, 2009). Pero no son sólo estas afinidades, todavía contingentes, las que sellan el vínculo entre trabajo creativo y capitalismo flexible. En un ensayo que reflexiona acerca de las contradicciones que signan a la práctica artística en el mundo contemporáneo, Kunst (2015) explora las proximidades entre arte y capitalismo, y se pregunta cómo dichas prácticas pueden desplegar discursos ejemplares de resistencia y crítica al sistema, a la vez que desenvolverse funcionalmente en su engranaje. La autora proporciona una sugerente clave de análisis al advertir que, entre las prácticas creativas y los modos de producción de subjetividad contemporáneos, parece existir una homología basal: lo que el arte y el capitalismo tienen en común, señala Kunst, "es la peligrosa y seductora cercanía de la apropiación de la vida" (2015, p. 21). Tanto el arte como el capitalismo, entonces, operan disolviendo las fronteras de lo que solía estar más allá de sus dominios, constituyéndose cada cual como una suerte de ética expansiva capaz de subsumir cualquier práctica u objeto. Por un lado, la vasta genealogía del binomio arte/vida da cuenta de los muchos caminos que han buscado esta fusión en la historia del arte: la vida cotidiana, la sexualidad o el propio cuerpo del artista han devenido no sólo instrumentos, sino la sustancia misma de las artes. Por el otro, tal como apunta Kunst, el "consumo radical" se encuentra en el centro del capitalismo contemporáneo, convirtiendo en activos económicos - y en plusvalor - aspectos tan inasibles e íntimos como las relaciones sociales, los valores éticos o los deseos y expectativas.

Estas afinidades estructurales entre el trabajo creativo y los modos de producción postfordista ofrecen una entrada relevante a las transformaciones contemporáneas del mundo del trabajo. Ya sea porque las prácticas laborales de los artistas son consideradas una vanguardia respecto de los cambios que experimentan otros sectores productivos, o porque representan un campo donde las formas de subjetivación del capitalismo tardío han permeado de forma exitosa, resulta relevante realizar un examen crítico de las condiciones que hacen posible la existencia de un sector productivo sobreadaptado a la precariedad e inseguridad social, que a la vez niega su propia condición trabajadora. Planteamos, en línea con la literatura internacional, que en el contexto metropolitano de la ciudad de Santiago de Chile los campos creativos y artísticos encarnan de forma paradigmática las contradicciones propias del trabajo en la era postfordista, y que una mirada a sus estilos de vida puede proporcionar luces acerca de los modos en que se redefinen, actualmente, las funciones y sentidos otorgados al trabajo. Para ello, será necesario identificar las prácticas y discursos que han configurado esta "forma de vida artística", en torno a la cual se anudan imaginarios, expectativas, creencias y modos de hacer. 


\section{El "giro creativo" en el trabajo contemporáneo: luces y sombras de un modelo laboral}

Afirmar que la práctica creativa constituye un referente para el mundo laboral contemporáneo encierra unas cuantas contrariedades que debemos despejar. Aunque existe cierto consenso respecto del valor social del arte y la cultura, sabemos que este aprecio pocas veces se materializa en reconocimientos económicos; que las carreras artísticas tienden a estar mal rankeadas y exigir bajos puntajes de admisión a sus postulantes; y que las expectativas de salario de estas ocupaciones son ciertamente desalentadoras. En este sentido, las labores creativas gozan de un estatus ambivalente en el mundo social, que bien podría ser resumido como una profusa celebración en lo abstracto, a la vez que un profundo desconocimiento en lo concreto. Es decir, nuestras sociedades tienden a exaltar la práctica artística como modo de vida, negándola al mismo tiempo en tanto labor productiva. Las siguientes secciones del texto, en consecuencia, se proponen retratar estas dos caras del problema: nos detendremos, en primera instancia, en aquellos elementos propios de los trabajos creativos y artísticos que reciben una atención social favorable en el marco de las transformaciones de la esfera del trabajo, explorando sus luces y sus sombras. En la siguiente sección, por su parte, pondremos de relieve aquellos aspectos que las exaltaciones contemporáneas al trabajo creativo tienden a omitir: observaremos el precario estatuto de dichas clases creativas en tanto sujetos laborales.

\section{a. Artistas, estilo de vida y ciudades creativas}

Tal vez la más evidente y seductora de las cualidades del trabajo artístico es la connatural estetización de la vida cotidiana que estas prácticas laborales acarrean. En tanto sectores especialistas en la producción simbólica y sujetos supuestamente liberados del peso de las constricciones sociales, los artistas y productores culturales son a menudo identificados como agentes dinamizadores de las tendencias, y sus modos de vestir, actuar y habitar el espacio son replicados en otros contextos como referentes de innovación y creatividad. Aun cuando no gozan de grandes retribuciones económicas por su trabajo, quienes se desempeñan en los campos artísticos tienen acceso a un estilo de vida marcado por formas del consumo que bien podríamos calificar de conspicuas, como los viajes al extranjero o la asistencia a eventos exclusivos. Los sectores creativos, en este sentido, han sido reconocidos como figuras "trendsetters", y sus modos de vida resultan atractivos para otros dominios productivos (Sánchez, 2016).

5. Para una discusión crítica de esta categoría, consultar García Canclini, Urteaga y Cruces, 2012. 
Aunque el imaginario bohemio y rupturista que se asocia a estas labores se remonta muy atrás en el tiempo, a inicios del siglo XXI, una oleada de perspectivas celebratorias del trabajo cultural cambió radicalmente la percepción social de su relevancia. En su influyente libro "La clase creativa" (2002), Richard Florida enfatizó las muchas bondades que estos grupos artísticos y "bohemios" traerían a las economías y las ciudades, otorgándole un lugar central en esta operación a sus sentidos estéticos y estilos de vida. Las "ciudades creativas" de Richard Florida - motores de una promisoria nueva economía - habrían de permitir a sus usuarios participar de experiencias culturales y estéticas próximas al mundo artístico, generando una "cultura a nivel de la calle" que incluía comercios creativos como cafés, bistrós, galerías de arte o tiendas de antigüedades, todo ello combinado con actividades informales - desde andar en bicicleta a disfrutar de un espectáculo de música callejera- en las que desaparecen las diferencias entre el participante y el observador (2002). Aunque el modelo de ciudades creativas de Florida recibió contundentes críticas tanto en lo ideológico como en lo metodológico ${ }^{6}$, sus consignas transformaron sustantivamente el panorama urbano de múltiples ciudades a lo largo del globo, cuyas administraciones reorientaron sus estrategias de desarrollo en base a la emergente "economía creativa".

En estricto sentido, los efectos de la presencia concentrada de agentes artísticos en ciertas zonas de las ciudades fueron advertidos décadas antes del auge de estos discursos. En un sugerente estudio realizado en los años ochenta, Sharon Zukin reconstruyó cómo los desplazamientos de los artistas en el Soho de la ciudad de Nueva York operaron como una fuerza gentrificadora que expulsó a los residentes históricos de sus barrios en nombre de las promesas de una "economía creativa" (2014). Más recientemente, Martha Rosler reactivó esta discusión exponiendo las contradicciones que atraviesan a los sectores artísticos, en tanto sujetos supuestamente comprometidos, progresistas y sensibles, pero cuyas prácticas residenciales y de consumo participan activamente de la devastación urbana (2017). En Santiago, ciudad en la que está emplazado nuestro estudio, también los artistas han desempeñado un rol relevante en los procesos de regeneración de algunos focos urbanos - como Barrio Italia y Bellavista-, inyectándoles un valor renovado que los convierte en "lugares con estilo", y les permite atraer nuevas inversiones, visitantes y habitantes con mayor poder adquisitivo (Schlack y Turnbull, 2011). El reverso de estas celebradas transformaciones del

\footnotetext{
6. Algunas de las críticas a esta formulación acusan el uso que se le otorga a la "creatividad" presentada como un recurso ahistórico y sin considerarla un producto de la actividad y la cooperación-; la omisión de la precarización que vive este sector; y la función política que poseería en tanto anuladora de conflictos. En relación a este último punto, se señala que la propuesta de R. Florida constituiría una teoría de la modernización que retoma la contracultura para convertirla en "una cuenca donde invertir en el capital humano propio y en una manera de hacer dinero" (De Nicola, Vercellone y Roggero, 2007, s/n).
} 
tejido urbano, también aquí, es el desplazamiento forzoso de los residentes originarios, y la profundización de la segregación en una de las ciudades más desiguales de América Latina (Bonilla, 2018).

\section{b. Trabajo flexible y pasión creativa}

Un segundo elemento que adquiere notoriedad en las celebraciones del trabajo creativo desde los discursos contemporáneos guarda relación con las libertades de un trabajo flexible que no sólo no conoce horarios: las propias fronteras entre éste y el tiempo libre parecen difuminarse. Aunque son excepcionales los estudios internacionales que se detienen en ello más allá de su mera constatación (Bille, 2010; Van Holm, 2014), la imbricación entre trabajo y ocio ha sido identificada como un aspecto central del campo laboral de las clases creativas: el arte, señala Kunst, se presenta como la representación ideal y más especulativa de la desaparición de la línea entre la producción y la reproducción (2015, p. 21). Las formas en que los artistas han gestionado históricamente el binomio trabajo/vida parecieran albergar la promesa de una existencia libre del tedio y el sinsentido de un trabajo esclavizante. En esa medida, este estilo de vida dilatado, signado por la autodeterminación, el estímulo constante y la actividad en base a proyectos (Groys, 2014), ha sido un referente clave para el diseño y gestión de los empleos de vanguardia en el siglo XXI, especialmente aquellos que se sitúan en el ámbito de la tecnología y la innovación, como es el caso icónico de Google Inc. (Girard, 2009). La flexibilidad y el borramiento de los límites entre trabajo y ocio constituyen elementos centrales de ciertas expresiones laborales del mundo postfordista concebidas como "trabajo significativo", en donde la actividad laboral se funde con el proyecto personal y posee una gran centralidad en la constitución identitaria de los sujetos (Overell, 2008; Valenzuela, Reygadas y Cruces, 2015). Quienes promueven estas contaminaciones comprendiéndolas como un "enriquecimiento vital del trabajo", subrayan que el trabajo significativo porta valores como la libertad, la diversidad y el interés, desplazando así las formas autoritarias y verticales de gestión por una cultura organizacional basada en la autodisciplina y la presión de los pares (Valenzuela et al., 2015). La motivación, en resumidas cuentas, augura una transformación revolucionaria en las culturas organizacionales emergentes, que trastocaría profundamente el balance trabajo/vida hacia un modelo laboral semejante al de los mundos del arte.

La indistinción entre los tiempos de trabajo y ocio en el mundo artístico no puede ser comprendida sin la dimensión gozosa y apasionada que los trabajadores culturales asignan a su práctica, pero esta supuesta felicidad encierra un conjunto de ambivalencias. A partir una revisión bibliográfica, Sinigaglia (2013) identifica que la representación dominante de la producción artística —en base al carácter prestigioso y la libertad de su actividad - lo configuran como un trabajo con todos los elementos para la "felicidad" de sus trabajadores. Sin embargo, ya sea porque el reconocimiento 
nunca llega o por las hostiles condiciones materiales que experimentan, este sentimiento de satisfacción en relación a su vida laboral se ve degradado en la mayoría de los artistas "ordinarios" (Sinagaglia, 2013). Siguiendo esta línea, la motivación intrínseca del trabajo creativo y el goce que lleva asociado representan armas de doble filo, cuyos claroscuros son difíciles de discernir con precisión. Nuestro trabajo de campo permite confirmar la relevancia de este componente vocacional y de autorrealización personal en el trabajo de los productores creativos y, en línea con diversos autores, identificar en este "entusiasmo" un flanco abierto a diversas formas de vulnerabilidad laboral (Gielen, 2009; Zafra, 2017). Aquí, al igual que el panorama global, la dimensión de la felicidad que parece atravesar las prácticas creativas tiende a convertirse en la retribución principal que reciben las labores artísticas, castigando a dicho sector productivo y exponiendo a sus trabajadores a una severa precariedad. Mauro, por ejemplo, apunta que nociones como la de "vocación" conllevan una exigencia implícita de subordinar la labor artística a fines no económicos (2018). De la misma forma, en la industria de la música argentina, Quiña confirma los diagnósticos internacionales que distinguen una invisibilización del trabajo creativo en aras de la consigna de "hacer lo que amas" (Tokumitsu, 2015), observando ya sea expresiones de "emprendedurismo forzado" (Oakley, 2014), o una relegación a un segundo plano del carácter laboral de la actividad artística que, a la vez, parece "humanizar" el proceso tercerizador (Quiña, 2018).

Aunque en las actividades artísticas el acople entre trabajo y pasión es estrecho y hasta puede ser planteado como prototípico (McGee, 2005), las contradicciones detectadas en estos campos también se presentan en otros ámbitos productivos estructurados en base a dicho modelo "entusiasta". Un estudio publicado en 2019 logró demostrar que la pasión posee un rol importante en la legitimación de malos tratos laborales y en la justificación de la explotación laboral (Kim, Campbell, Shepherd \& Kay, 2019). Si bien existen muchas investigaciones que pregonan los efectos positivos de estas modalidades de trabajo marcadas por el goce y el compromiso, las consecuencias negativas de éste han sido menos documentadas: en este estudio, indican que la pasión puede llevar a un mayor agotamiento y menos flexibilidad de objetivos (Vallerand et al., 2003; Vallerand, Paquet, Philippe, \& Charest, 2010, citado en Kim et al., 2019), y que el trato explotador - comprendido como el hacer sacrificios por el trabajo, o desempeñar tareas degradantes no vinculadas a la descripción del trabajose considera más legítimo en el contexto de profesiones que están más fuertemente asociadas con la pasión (Kim et al., 2019).

En síntesis, en el contexto de los procesos de flexibilización del empleo y reestructuración laboral contemporánea, el profuso llamado a un "giro creativo" del trabajo ha operado seleccionando ciertos elementos de la práctica artística. El estilo de vida de los artistas, sus patrones residenciales y de consumo, sus modos dilatados de mezclar 
el trabajo y la vida, y el compromiso apasionado con la propia labor forman parte de un ethos laboral que ha ido, de esta forma, expandiéndose más allá de los artistas. Sin embargo, moldeados por las lógicas neoliberales y sus imperativos de productividad, estos elementos tienden a esconder contradicciones y efectos no deseados que pueden vulnerar las condiciones laborales de los trabajadores y la sustentabilidad de sus entornos. Si bien algunos de sus aspectos problemáticos también son perceptibles en los demás sectores productivos, pensamos que examinar los costos materiales y subjetivos que enfrentan los creadores culturales en su ejercicio profesional puede ofrecer un contrapunto valioso a las exultaciones de la economía creativa.

\section{Los costos subjetivos del trabajo creativo}

En las últimas décadas, desde el campo de la investigación social, ha cobrado forma un vasto diagnóstico de las condiciones laborales de los sectores creativos, en el que se distingue la precariedad como un atributo central de estos ámbitos productivos. Sin embargo, ¿cómo es posible hablar de precariedad laboral en un sector cuyo estilo de vida es exhibido como referente para el resto de la sociedad e, incluso, como un modelo de felicidad respecto del balance trabajo/vida? ¿Es posible asimilar estas formas de la inseguridad laboral a las que enfrentan las clases trabajadoras tradicionales? En tanto los trabajadores inmateriales y creativos comparten un conjunto de preocupaciones con los trabajadores más vulnerables del mercado laboral, hay quienes han avizorado allí la posibilidad de emergencia de una nueva categoría multiclase: el precariado (Raunig, 2007; Raunig, et al., 2011; Tsianos y Papadopoulos, 2006). Acaso el sucesor postfordista del proletariado, el precariado pareció - en primera instanciaalbergar la potencia de remecer los modos de operación del trabajo en el capitalismo flexible. Si bien las experiencias comunes de la incertidumbre radical respecto del futuro; el carácter intermitente (o, directamente, la informalidad) de los contratos de trabajo; y la exclusión respecto de todo instrumento de seguridad social no han sido suficientes para lograr una "unidad de conciencia y acción" interclase (Ross, 2009), durante las últimas décadas observamos una creciente visibilización de estas hostiles condiciones objetivas, y un incremento a nivel internacional de agrupaciones colectivas por la defensa de los derechos laborales de los artistas y creativos.

Dado el amplio espectro de actividades y perfiles contemplado en nuestro estudio, y en línea con las descripciones realizadas por otros autores en diferentes campos (Guadarrama, Hualde y López, 2012), observamos que el trabajo creativo en Santiago de Chile involucra realidades altamente heterogéneas, tanto al interior de las disciplinas como entre ellas. Marcados distintivamente por la flexibilidad laboral, quienes se desempeñan en el ámbito artístico y creativo tienden a ejercer modalidades de trabajo no atípico, a través de "formas variadas de alejamiento de la norma ideal de empleo, de origen fordista" (Guadarrama et al., 2012, p. 216). Sintetizaremos, en base a tres 
ejes temáticos, los principales aspectos en los que se expresa la precariedad de los sectores artísticos y creativos, poniendo en diálogo la literatura internacional con los hallazgos de nuestra investigación.

\section{a. En torno al tiempo}

Las expresiones de la flexibilidad de estos sectores productivos los lleva a experimentar una amplia diversidad de regímenes laborales no sólo a lo largo de sus carreras, sino incluso de forma simultánea. Aunque el trabajo por proyectos (García Canclini et al., 2012; Oliva, Iso y Feliu, 2012) se presenta como modalidad privilegiada en las más diversas disciplinas creativas, ésta no es excluyente respecto de otros contratos y arreglos, tanto formales como informales. Tal y como ha sido apuntado a nivel internacional, nuestros hallazgos confirman que el trabajo creativo se caracteriza por la multiactividad (Gerber y Pinochet, 2012; Guadarrama, 2014) o el pluriempleo (Oliva, 2017), y que involucra el despliegue de ciertas "ecologías" del trabajo en las que la labor artística convive de maneras diversas con las tareas administrativas y con otras actividades auxiliares (Sinigaglia-Amadio y Sinigaglia, 2015). Además, nos enfrentamos a un tipo de ocupación que obliga a problematizar toda oposición estricta entre categorías que usualmente se utilizan de forma binaria: el tiempo de formación y el ejercicio profesional; el empleo y la cesantía; el trabajo y el ocio. Así, en estas escenas artísticas y culturales, así como en otros contextos nacionales, podemos afirmar que "la dimensión central de la precariedad del trabajo artístico es la temporal" (Guadarrama, 2014, p. 32), no sólo porque su característica intermitencia conlleva diversas fuentes de inseguridad e incertidumbre, sino también porque el desdibujamiento de las fronteras entre el trabajo y la vida implica que todo tiempo es potencialmente empleable. La dimensión del tiempo, como veremos más adelante, es el origen y el fundamento de una de las ambivalencias centrales de este tipo de actividades, y en torno a ésta se anudan un conjunto de contradicciones que no han sido suficientemente visibilizadas.

\section{b. En torno a la retribución económica}

Un segundo rasgo en el que nuestro trabajo de campo se alinea con los hallazgos internacionales consiste en las dificultades y resistencias que existen para traducir la producción creativa a un beneficio económico. Los trabajadores y trabajadoras del arte y la cultura se desenvuelven en un medio en el que es frecuente y, hasta cierto punto, mandatorio, realizar trabajo impago: actividades que, aunque usualmente recibe retribución económica, no son cobradas en tanto favor o forma de difusión del trabajo creativo (Quiña, 2018). El concepto de «trabajo sumergido» de Paolo Virno da cuenta, precisamente, de aquella vida no retribuida: se trataría de "la parte de la actividad humana que, pese a ser homogénea en todo con aquella parte que pertenece a la esfera laboral, no es computada como fuerza productiva" (Virno, 2008, p. 117). 
Es importante poner de relieve que no es tan sólo un "sistema perverso" que obliga a los creadores culturales a trabajar sin remuneración, sino que muchas veces cobra la forma de una trama de sociabilidades y economías afectivas que operan desconociendo, parcial o totalmente, la naturaleza productiva $-\mathrm{y}$, por tanto, económica- de estas actividades. Los artistas y creativos participan de cadenas de favores atravesadas por relaciones humanas, códigos éticos y sentidos de lo político, en las que son involucrados e involucran a otros en la realización de estas actividades impagas. Predomina en su ejecución el ya mencionado sentido del placer, la vocación y la gratificación que les ofrece el trabajo creativo en sí mismo; las lealtades, complicidades y deudas con otros que se pagan poniendo a disposición su propia fuerza productiva; y las expectativas de visibilidad y de capitalización simbólica de la presencia pública que viene con dicho trabajo. De este modo, no encontramos en nuestro trabajo de campo la idea de que la lógica artística sea excluyente del beneficio monetario - como identifica Mauro (2018) - , pero sí observamos que existen otras economías afectivas (la del placer; la del favor; y la de la visibilidad artística) que adquieren prioridad respecto de los intercambios propiamente económicos. Estos desacoples entre trabajo y dinero afectan especialmente a los artistas y creativos que se encuentran en las fases iniciales de su carrera, pero no desaparecen del todo ni siquiera cuando se alcanzan espacios de reconocimiento destacado dentro del campo. Si bien para los más jóvenes es una fuente cotidiana de preocupación y angustias, para los artistas consolidados no deja de ser un asunto frustrante, sobre todo cuando estas exigencias de trabajo impago provienen de instituciones estatales. Aunque los subsidios al arte y la cultura admiten el cobro de honorarios a quienes crean y ejecutan los proyectos - a diferencia de Argentina, donde Mauro señala que no es posible financiar este tipo de gastos (2018)-, éstos resultan siempre insuficientes: buena parte del trabajo artístico y creativo es implícitamente "subvencionado" por los propios trabajadores que lo producen. Así, merodeando la escasez y la opacidad, la relación de los sectores creativos con el dinero conforma un segundo campo de ambivalencias, cuyo signo negativo dificulta la adscripción de sus actividades al dominio del trabajo.

\section{c. En torno a la gestión}

Un tercer eje que adquiere relevancia al caracterizar las condiciones laborales de los productores culturales invita a problematizar los dos anteriores - el tiempo y el dinero-. Si la experiencia del tiempo se encuentra marcada por la intermitencia y simultaneidad de la lógica de los proyectos, así como por la condición expansiva y la indistinción entre el trabajo y el ocio; la experiencia en torno al dinero de este sector productivo está condicionada por la escasez de los recursos, la incertidumbre respecto del financiamiento y la opacidad de las operaciones de conversión del trabajo en retribución económica. En esa medida, una tercera dimensión que atraviesa las condiciones laborales de los campos creativos es la necesidad de gestión permanente 
de las propias condiciones de producción. Este enunciado amplio apela, dentro de los diversos perfiles que cubre el estudio, a circunstancias disímiles, que van desde la obligación de conseguir el financiamiento de los propios proyectos -incluyendo idear, formular, ejecutar y rendir-, a proveerse de un espacio y de un tiempo compatible con las actividades creativas que realizan.

La gestión del tiempo y de los recursos en los sectores artísticos y creativos a menudo adquiere la forma prototípica del autoempleo, presentando grados relativos de formalización o autoconsciencia de esta figura. Nuestros informantes dan cuenta de sus iniciativas desde conceptos como "autogestión" o simplemente "proyectos": la idea del "emprendimiento cultural", que proliferó en lugares como Inglaterra o España con el auge de las economías creativas, tiene una resonancia limitada —al menos como discurso- en nuestro levantamiento empírico. En una escena periférica como la santiaguina, donde el potencial económico de las industrias creativas es más un recurso publicitario que una vía efectiva para surgir económicamente, el "emprendedor cultural" que perfilaba Rowan - aquel que, en nombre de la creatividad, capitaliza los acervos culturales comunes para obtener réditos económicos (2010) - tiene escaso arraigo en los circuitos creativos locales. Los entrevistados de esta investigación, incluso cuando participan de entidades que prestan servicios y venden productos, suelen remarcar la brecha entre los intereses de la empresa y los de ellos mismos: el emprendedurismo, como modo de subjetividad, no aparece como un elemento relevante dentro del ethos laboral de los sectores creativos locales. Son, ciertamente, trabajadores a la deriva que engrosan las filas del boletariado ${ }^{7}$, y cuya suerte depende casi exclusivamente de su propio rendimiento en el medio cultural. Esta condición "a cuenta propia”, sin embargo, pocas veces es representada desde la lógica del emprendimiento y de la capitalización de la producción creativa. En las pocas excepciones registradas, como la que observamos en la cita a continuación, los "emprendimientos" se ven revestidos de una condición de simulacro, que permite a los agentes culturales participar estratégicamente de sus beneficios y a la vez ganar cierta distancia crítica respecto de esta retórica.

"En algún momento, sentí que había llegado a un tope de trabajo como independiente. $\mathrm{O}$ empezaba a trabajar en algo fijo, o siempre iba a tener trabajos de muy baja remuneración. Entonces, me vine a Santiago y me empleé por primera vez en mi vida. Fueron dos años de un proceso en el que fui observando cómo trabajaba la gente... [...] Ahí apareció la idea de armar un estudio de creatividad. En el estudio estaban todas las variables que yo que-

\footnotetext{
7. En clara alusión al concepto de "proletariado", el "boletariado" en Chile refiere a la colectividad de los trabajadores que no poseen contratos - y por ende, seguridad social alguna-, realizando sus actividades productivas de forma independiente y contra boleta de honorarios.
} 
ría trabajar, pero no se verían asociadas a mi nombre, sino a un equipo que era un estudio. Entonces, en el fondo yo siempre fui un ente solo que trabajaba conmigo, pero cuando era el momento de necesidad, yo me asociaba con otras personas. Es distinto que tú me contrates a mí a que contrates un estudio, y eso fue lo que hizo el respaldo para poder crecer en este tipo de trabajos. Yo y mis cincuenta mil imaginarios. [...] Eso me hace sentir a mí también una auto-sensación de grandeza, de que todo funciona, de que todo avanza... pero al final eres tú tu propio minion atrás" (C-M-T1 $)^{8}$.

En otros casos, aun cuando esa necesidad de autorregular los propios tiempos y actividades es nombrada sarcásticamente como "el emprendimiento que es uno mismo", el quehacer creativo encuentra una metáfora de referencia — paradójicamenteen el extremo opuesto de los imaginarios laborales: en el trabajo burocrático.

"Estaba asesorando Fondart, formulando yo un proyecto, respondiendo un montón de correos y cuestiones así... Básicamente, trabajo de oficina no remunerado que uno tiene, de la propia gestión del emprendimiento que es uno mismo. [...] Trabajé un año en Fondart como supervisor de proyectos y lo que observo ahora cuando estoy sentado frente al computador, en mis cosas, es exactamente lo mismo [...] que pasa en el aparato burocrático estatal. En el fondo, siempre hay mil pendientes que están esperando por ti, y que en la medida en que tú empiezas a escarbar un poquito aquí, emergen cinco más» (I-H-T1).

Sostenemos que esta tercera dimensión del trabajo creativo, la de la gestión permanente de las propias condiciones laborales, constituye en sí misma una carga un trabajo- insuficientemente visibilizado. Cada una de las dimensiones descritas anteriormente se encuentra atravesada por profundas contradicciones: gestionar los tiempos de los creadores culturales implica arbitrar la simultaneidad y la indistinción; gestionar sus recursos económicos conlleva administrar las carencias y la inseguridad. En esa medida, la compatibilización de ambas parece una tarea imposible; un ejercicio de equilibrismo. En nuestro trabajo de campo, se hizo patente que esta gestión de las fronteras entre el trabajo y la vida tiene, para los creadores culturales, una serie de costos subjetivos considerables, que no siempre son registrados como tales. Entre éstos, además de puntos ya mencionados como la multiactividad, la incertidumbre, la precariedad contractual y el trabajo sumergido, sobresalen dos elementos

8. Esta cita - así como también las próximas - corresponden a extractos textuales de las entrevistas realizadas a los participantes. Para caracterizarlos se utilizará la siguiente nomenclatura: (1) Subcampos: Artista (A), Creativo (C), Intelectual (I); (2) Género: Hombre (H), Mujer (M); (3) Edad: Tramo etario menor de 40 años (T1) y Tramo etario mayor a 40 años (T2). 
que se encuentran presentes entre informantes de los perfiles más diversos, tanto a lo que respecta a la disciplina, como a la edad y el género: por una parte, la sobrecarga laboral, y por la otra, el compromiso emocional que involucran estas actividades.

La sobrecarga de trabajo, que afecta tanto a trabajadores hombres como a trabajadoras mujeres en distintos momentos de su carrera artística, aparece a menudo disimulada por las retóricas de la vocación y la gratificación del trabajo creativo. Sin embargo, los registros de las bitácoras de autoseguimiento etnográfico fueron elocuentes al señalar la gran cantidad de actividades laborales realizadas en cada jornada, y el ostensible carácter intensivo que suelen cobrar estas dinámicas de trabajo. "El trabajador del conocimiento ejemplar, el compañero o investigador admirado — señalan Oliva, Iso y Feliu (2012) al hablar de los "patios traseros" de la economía creativa-se describe así como alguien sin tiempo personal, inmerso en sus tareas y capaz de una dedicación excepcional" (p. 61). Nuestros entrevistados relatan sus extenuantes jornadas de trabajo como prácticas expansivas, que generalmente desconocen los límites entre los días hábiles y los fines de semana, o entre el tiempo laboral y las vacaciones; que no se ralentizan lo suficiente durante los períodos de enfermedad o inhabilidad; y que no proyectan un término esperable en el momento de la jubilación o retiro. Para quienes ejercen la maternidad o paternidad, el ritmo de trabajo ha significado importantes esfuerzos para compatibilizar la alta carga de labores, lo que tiende a realizarse construyendo puentes entre ambos mundos. En muchos casos, especialmente en las mujeres del campo intelectual, esta opción laboral ha ido de la mano de una decisión de no ser madres, que si bien no se experimenta necesariamente como un costo o una pérdida, sí han debido destinar una importante energía psíquica en elaborar lo que significa ser una mujer sin hijos en la sociedad contemporánea. En este compromiso irrestricto con el proyecto laboral convergen razones múltiples: la ya nombrada autorrealización a través del trabajo; la introyección de un ethos laboral basado en la autoexigencia, regulado por el reconocimiento de los pares y, en algunos casos, tensionado por la competitividad; y sobre todo, la necesidad imperiosa de aumentar los ingresos económicos. Para la mayor parte de los participantes de este estudio, esta ecuación que pondera tiempos y recursos económicos implica tomar decisiones: o emplearse parcialmente en contextos laborales poco o nada relacionados con su ejercicio creativo, o ampliar sus horas laborales aceptando más proyectos y responsabilidades que las que cabrían en una jornada de trabajo convencional. Los siguientes extractos de entrevistas resumen una realidad que, salvo contadas excepciones, resulta transversal a los campos creativos:

"Nosotros los independientes trabajamos más que la cresta. Trabajamos mucho. Trabajamos a deshoras. Cuando digo que no trabajo los sábados y domingos, es mentira porque también tengo un puesto en Franklin con unos amigos y voy a vender [...] Entonces, al final uno trabaja más que un 
asalariado. Creo que para él sería un poquito más fácil cortar. Uno trabaja a deshoras mucho, entonces tienes que aprender ciertas formas de salirte de esa pega entremedio, y aprovechar ciertos bolsones de aire que tiene" (C-H-T2).

“Todos mis amigos me dicen que no entienden cómo yo logro hacer cosas con el poco tiempo que tengo, pero es porque, de verdad, tiempo que salgo de clases o que no estoy en clases, estoy produciendo. Estoy pensando, haciendo, trabajando de noche, y me quedo hasta las tantas. Solamente recurro a la desconexión de este mundo cuando estoy muy cansado. Eso no pasa todos los días, pasa un par de veces a la semana" (A-H-T1).

“Te sobreexiges en la medida que tú cachas que puedes. O sea, había días en que igual estabas a las seis de la mañana escribiendo una plana con suerte, estabas muchas horas pegado con una cosa muy chica y a las diez tienes que estar igual trabajando. Pero como que vas asumiendo eso, y es parte del placer de crear también» (A-H-T1).

La experiencia de los trabajadores culturales se encuentra, en consecuencia, determinada por la sobrecarga y la persistente percepción de que no existe un afuera del trabajo. "Es como una especie de rueda donde tú tienes que ir siempre corriendo, como las ardillas esas", nos señala una entrevistada del campo intelectual (I-M-T2). Es por ello que las bitácoras registran días laborales que suelen terminar con declaraciones de cansancio y agotamiento, especialmente en los casos de las mujeres que deben compatibilizar - en mayor medida que los hombres - el trabajo creativo con las labores domésticas y de cuidados. "Me pareció interesante eso de preguntarse cómo uno se siente - reflexiona otra informante acerca del proceso de auto registro en el marco de este estudio-. Uno escribe "cansado", "cansado", todo el tiempo, pero también, de repente me di cuenta que claro, estaba cansada pero entretenida" (I-M-T2). Nos parece que este último punto es clave: si bien quienes se desempeñan en los campos creativos deben hacer frente a un trabajo extenuante, junto a esta constatación, los entrevistados suelen remarcar las satisfacciones que les brindan estas actividades, o la convicción de haber elegido - y continuar eligiendo - este modo de vida. Desacreditar estas asociaciones entre trabajo creativo y gratificación en tanto illusio (Bourdieu, 2016) impediría — como propone la sociología pragmática de Heinich (2002) - comprender la complejidad de los sentidos que los actores otorgan a sus acciones (Pinochet Cobos, 2020).

El segundo elemento que creemos importante remarcar guarda relación con la gestión de los estados emocionales que el trabajo creativo suscita. El modelo laboral comprometido que estas actividades demandan establece un estrecho vínculo entre trabajo y afectos, tanto porque se trata de actividades donde los vínculos personales 
directos tienen gran centralidad (Quiña, 2018), como porque el alto nivel de identificación con el propio trabajo conforma identidades laborales donde resulta difícil escindir el trabajo de la vida. En las labores creativas, en tanto "trabajo significativo", se despliega una gama de emociones cotidianas intensas que los trabajadores culturales deben aprender a regular (e incluso, a productivizar): puesto que los artistas y creativos responden por su trabajo, principalmente, ante sí mismos ${ }^{9}$, esta gestión emocional constituye una dimensión fundamental de sus desempeños e incide directamente en su trabajo. Dentro de este espectro conviven emociones positivas como la gratificación, el goce, la sensación de libertad, o el entusiasmo por los desafíos que se les presentan; con emociones negativas como la angustia, la ansiedad, la culpa, el agobio, la tristeza y la frustración. Así, mientras las primeras refuerzan las opciones tomadas y confirman la vocación y las habilidades para el trabajo desempeñado, las segundas pueden convertirse en serios obstáculos para persistir en este camino, y con cierta frecuencia derivan en problemas de salud mental que exigen cuidados médicos.

“Trabajé harto en psicoanálisis esta cuestión que me pasaba, y que me calaba muy hondo. Por ejemplo, si hacía algo mal y si alguien me cachaba y me encaraba, yo sentía que me caía en un precipicio. Siempre me acuerdo que mi analista me decía: “ ¿te das cuenta la huevada que estás diciendo? ¿Que te estás cayendo a un precipicio solo porque te enfrentaron?". Claro, siento que ese lugar que ocupa el trabajo en mi vida también ha calado; también me ha hecho tener una cierta costumbre en el modo en que me relaciono con ciertas personas" (I-H-T1).

“También lo asocio con salud mental, que siempre ha sido un problema... ya sea por el modo de vida, por la angustia que genera la precariedad o todo, siempre he tenido problemas de ansiedad y de angustia, que me ha costado mucho resolver y que vienen de chico. Entonces siento que ahora estoy re bien, pero estoy con psiquiatra, con medicamentos, con terapia. Siento que de algún modo mi identidad autoral en el trabajo ha estado también muy atravesada por mi nivel de ansiedad, que podría ser positivo incluso" (I-HT1).

\footnotetext{
9. Aunque es frecuente que los trabajadores culturales tengan contrapartes en ciertos proyectos e iniciativas particulares, e incluso que algunos de ellos cuenten con contratos donde son subordinados, las carreras creativas se estructuran en torno a metas autónomas. Ello entronca con los modos de subjetivación del capitalismo flexible, ya señalados anteriormente como el paradigma del "empresario de sí mismo", pero - creemos- no es del todo reductible a este modelo. Estas reflexiones serán retomadas en la sección final del artículo.
} 
La regulación de los estados de ánimo constituye, de esta manera, una parte importante de esa gestión de las condiciones de producción de la creación cultural. Los modos en que logran lidiar con la culpa - "una es culposa, y, una trabaja todo el rato para no sentirse con culpa. Claro, me da culpa tener culpa, más encima”, señala una entrevistada (Intelectual, T2) - puede marcar significativamente el desarrollo de una jornada laboral; encontrar una forma de enfrentar - y de productivizar - las frustraciones y las angustias que forman parte de este estilo de vida laboral puede dividir entre aquellos que perseveran en los mundos del arte y quienes deciden renunciar a ellos. Además, se suma la importante tendencia a la reflexividad que portan muchos de los productores culturales: en tanto insumo fundamental de los procesos creativos, la constante atención a sí mismo y al entorno lleva a estos trabajadores a desarrollar altos grados de autoconsciencia acerca de sus prácticas laborales, comprometiéndolas tanto intelectual como afectivamente.

\section{Tácticas y estrategias en la gestión del trabajo creativo}

Este particular estatuto del tiempo y de la retribución económica en el trabajo creativo, sometido a permanente (auto)gestión, obliga a quienes se desempeñan en estos campos a modelar sistemas que les permitan navegar la precariedad y la incertidumbre. Los hallazgos de nuestro trabajo de campo nos permiten distinguir dos expresiones de estos sistemas de acuerdo a su alcance y proyección. Apelando a sus acepciones en el lenguaje común antes que a las definiciones de De Certeau (1996), las nociones de "táctica" y "estrategia" nos permiten dar cuenta de los diversos órdenes de disposiciones que los trabajadores de las escenas creativas establecen para administrar las difuminadas fronteras entre el trabajo y la vida. Mientras las tácticas -el arte de poner las cosas en orden- les ayudan a controlar las vicisitudes de la vida diaria para poder procurarse un tiempo/espacio propicio para el trabajo creativo; las estrategias - reglas que aseguran la idoneidad de cada una de las decisiones tomadas - ofrecen una perspectiva global que da forma a sus carreras creativas en el largo plazo. Táctica y estrategia, en este sentido, se corresponden con el método y el plan; con la vida laboral cotidiana y la trayectoria profesional como un camino de largo aliento.

En el dominio de la gestión cotidiana, uno de los principales problemas que se les presenta a los trabajadores creativos - en tanto sujetos paradigmáticos del trabajo flexible- es la relativa ausencia de estructuras externas y objetivas respecto de las cuales ajustar sus actividades productivas, así como la falta de mecanismos de control que administren la progresión de la propia labor. En esta medida, muchos de los productores culturales desarrollan, apoyados en tecnologías análogas y digitales, sus propios sistemas para organizar el trabajo, para recordar las ideas que emergen en momentos inesperados, o para arbitrar los usos del tiempo en sus múltiples actividades. La planificación de actividades en agendas y cuadernos adquiere gran centralidad 
en muchos de nuestros entrevistados, y generalmente va asociada a la percepción de un bienestar interno: "Es muy importante, muy importante, muy importante", insiste una participante que se desenvuelve en el campo de la música, acerca de la organización de su productividad. " $Y$ además, sicológicamente me hace muy bien" (A-MT1) - . Como en otros trabajos, también en los sectores creativos el tener y percibir control sobre las tareas ayuda a reducir el estrés laboral (Durán, 2010). En la misma línea, una investigadora de las artes nos comenta:

“Tengo, por lo general, mi lista de cosas por hacer diarias, de cada dos días, de cada semana, mensual y después semestral. Siempre escrita a mano. Sólo funciono con cuaderno y con agenda. Tengo que escribirlo para saber que lo tengo que hacer. Y por lo general, así controlo la ansiedad. Yo sé que si tengo que entregar un texto en tres meses más, entonces a partir de un mes lo empiezo a poner todas las semanas" (I-M-T1).

Los tiempos de trabajo creativo, especialmente en sus dimensiones más solitarias, encuentran estructuración en sistemas externos, a menudo "artificiales" o inventados, que operan como contraparte de la indistinción interna que suele caracterizar los procesos creativos. Tal y como ha sido analizado en el mundo artístico a lo largo de los tiempos, los estilos adoptados por los creadores en su proceso de producción demuestran una gran variabilidad en sus rutinas (Currey, 2014), y a menudo los límites de esos sistemas se corresponden con los vínculos con otros: con responsabilidades familiares, o con sociabilidades que implican adaptarse a los horarios de los demás. Nuestros resultados ponen en escena una serie de tácticas cotidianas para administrar la propia producción; mecanismos que ayudan a ponderar el tiempo trabajado y los productos obtenidos de aquella jornada. Se trata de cálculos íntimos, arreglos personales y matemáticas internas, que rutinariamente construyen ciertas fronteras entre el trabajo creativo y todo lo demás: el ocio, las labores domésticas y de cuidados, el empleo si es que existe.

“Mis tiempos de producción como artista están protegidos con una cuestión que inventé cuando vivía en Estados Unidos. Me dije a mí mismo que tenía que trabajar una hora al día, aunque fuera rellenar el Excel de las tomas que tengo. Siempre he tenido ese problema porque tengo un déficit atencional cuático. Intento que el trabajo sea de una hora al día, algo con lo que pueda ir a dormir y decir "hoy día hice algo" (A-H-T1).

Muchas veces estos cálculos adquieren la forma de negociaciones consigo mismos, que se ajustan o se apartan de un deber ser imaginario del trabajo, frecuentemente inspirado en la jornada laboral asalariada (oficina fija, horario de nueve a seis, supervisión constante). En ocasiones, los artistas compensan el tiempo perdido a través de jornadas intensivas o, por el contrario, se conceden a sí mismos el derecho 
a descansar o a tener tiempo libre. Por ejemplo, un informante del estudio que se desempeña principalmente en el mundo académico señala que se "auto-otorgó" una licencia, tras vivir el duelo de un familiar cercano: "Y fue como: 'ya, sí, aquí de verdad tienes una licencia universal para no hacer nada.' Es como una excusa válida, es como si tuvieras un certificado médico" (I-H-T1).

A todo ello se suma la distintiva interpenetración del trabajo y la vida, mediada —en la línea de lo sostenido por Nippert-Eng (1996) - a través de objetos, personas y espacios físicos que no admiten recortes estrictos ni categorizaciones excluyentes. En este dilatado modelo de trabajo observamos una permeabilidad ambivalente: así como todo tiempo de trabajo puede ser fácilmente interrumpido por alguna forma de ocio - una oportunidad o una invitación imperdible, o la simple postergación de la labor para el día siguiente-, también resulta difícil dar con un tiempo de ocio verdaderamente a salvo del trabajo. Así, es preciso desdoblar los esfuerzos: no sólo buscar formas de crear tiempo para el trabajo creativo, sino también propiciar maneras de disponer de un tiempo libre a salvo del propio trabajo. Esta clase de tácticas también se materializa en el plano de lo cotidiano. Algunos entrevistados, por ejemplo, dan cuenta de los modos que han generado para colonizar la propia práctica profesional, otorgándole un sello personal que puede ser pensada como un desvío respecto del camino más lógico o más eficiente. En la cita a continuación, oímos la voz de un arquitecto que relata formas alternativas de realizar una tarea que, aunque ciertamente no serán apreciadas por la inmobiliaria que encarga el proyecto, hacen posible un goce en el proceso. En la misma línea, el siguiente fragmento da cuenta de la aproximación de un artista a la vida cotidiana, "lentificando" los tiempos útiles.

"Hay ciertas actividades que las asocio a una especie de complacencia [...] Como dibujar un plano a mano, o sea, un esquema de un terreno. A mí me produce mucha satisfacción hacerlo, porque es algo más instintivo. Se producen ineficiencias a raíz de eso, por creer que hay otras formas de hacer las cosas, y que quizás yo tengo otras formas, distintas a las de mi colega. [...] Finalmente, voy a llegar a un resultado similar, quizás. Pero me tengo que permitir explorar otro camino" (C-H-T1).

"Entre las actividades que hago, tengo tiempos muy, muy grandes. Normalmente hago muchas cosas a pie y parto para llegar a una hora muy adelantada. [...] Entonces, eso hace que me demore muchísimo: almuerzo, me voy para allá, doy la vuelta, voy caminando. En ese sentido, los tiempos que podría llamar de ocio más bien son tiempos útiles muy lentificados" (A-H-T2).

Pero también la gestión de fronteras debe proyectarse en el largo plazo, en función de la perspectiva de una carrera. Este nivel, que aquí nombramos como el de las estrategias, involucra un sentido acumulativo del quehacer productivo, y una consciencia 
del costo alternativo que tienen las diferentes elecciones en el curso de la trayectoria. En este sector productivo, la tensión que cruza más claramente la toma de decisiones es la que se establece entre administración y creatividad; o, en otros términos, entre los trabajos - creativos o no- realizados para otros y los trabajos experimentados como propios. Esta última categoría, movilizada por informantes de todo el espectro de la muestra, resulta crucial para comprender por qué los trabajadores de los sectores artísticos y creativos tienden a mostrarse gratificados con su vida profesional, incluso cuando sus condiciones laborales están surcadas por la precariedad y amenazadas por diversas fuentes de vulnerabilidad. El trabajo experimentado como propio, último bastión de la autonomía artística en tiempos postautónomos (García Canclini, 2010), puede incluso conformar una parte pequeña de la producción de un artista o agente creativo, pero infunde de sentido su labor de una manera gravitante.

"Si uno piensa en eso que uno quiere proteger, lo que le importa, o donde uno deja así como su humanidad, si po: la escritura" (I-M-T2).

"Me recuerda a una escena de "Gladiador", donde el personaje de Russell Crowe tenía un esclavo que durante la noche hacía unas figuritas para su familia. Entonces, Russell Crowe le pregunta al esclavo: “¿Cuándo tienes tiempo para hacer eso?” y él responde: "Bueno, la mayoría del tiempo hago lo que tengo que hacer y con lo que queda, hago lo que quiero". Eso me parecía una buena disposición. Ahora creo que uno muchas veces es esclavo de las cosas que tiene que hacer y es importante encontrar esos pedacitos de tiempo que son tuyos. [...] Creo que hoy vivo como el esclavo de Russell Crowe. Tengo unas cosas que sé que son mías y que las quiero mucho, valen más que el tiempo que duran. Entonces, si tienes algunas cosas que valen más que el tiempo que duran, está todo bien" (A-H-T1).

Es importante enfatizar que no necesariamente se trata de las facetas más reconocidas o exitosas de la producción de un trabajador creativo, ni tampoco es siempre una actividad gozosa y disfrutable. Es aquel trabajo que compromete a los agentes culturales en sus dimensiones más humanas y personales, y sobre el cual proyectan un valor trascendente - un sentido - que va más allá de una mera actividad laboral. Por lo mismo, están dispuestos a invertir sus recursos en éste aun cuando ello no ofrezca recompensas materiales, o lo haga muy a largo plazo.

"Hay momentos en que he ganado cero, que he pagado yo cosas, muchas, que hay que ir a una reunión en Argentina y hay que estar y - ponte tú- el circo no tiene plata. Y digo: 'ya, bueno". Y voy y pongo mi tarjeta; y voy y pago el pasaje; y voy porque tengo que ir. Harto de eso po. Muchas veces he subvencionado cosas, muchas... pero también el circo me ha mantenido 24 años de alguna manera y he vivido del circo" (C, M, T2). 
El lugar en que los artistas sitúan este "trabajo experimentado como propio" no se resuelve solamente en los acomodos de la vida cotidiana: es a menudo una decisión consciente, que moldea el curso de sus carreras y ejerce su peso en la toma de decisiones. Algunos de nuestros informantes evitan que esas producciones más personales circulen como mercancías, o establecen límites a estas transacciones distinguiendo de modos diversos entre el "trabajo" y la "obra" (Mitrovic, 2020). Como contraparte del trabajo propio, nuestros informantes generan mecanismos para poner a raya el "trabajo" a secas: en éste resulta más sencillo ponerle un valor económico a la propia labor, y en consecuencia, concebirse a sí mismos como trabajadores que venden su fuerza productiva.

"Mucha gente vende su técnica, y la obra no la vende. Y eso le da un cierto espacio de libertad y autonomía para no depender del mercado y todo ese problema que se puede generar a partir de mercantilizar la obra" (C-H-T1).

"Con una amiga ilustradora acuñamos el concepto de «trabajo salchicha». Los trabajos salchichas son eso: tienen que ser rápido, y no son muy ricos. Los "trabajos salchicha" al final se convierten en una gran cadena de salchichas... [...] son cosas en que ya no me involucro creativamente. Y trato sí de lograr cierta dignidad y que no me dé vergüenza mostrarlo, y que sea profesional y todo, pero no... intento que no haya una demanda, ni un gramo más de lo que necesita eso, porque va a un saco roto de energía de creatividad" (C-M-T2).

El despliegue de estrategias, en este sentido, permite a los agentes culturales poner sus múltiples habilidades y recursos al servicio de un proyecto de vida, que sitúa el lugar del trabajo - generalmente, prioritario- en la existencia y, dentro de éste, el de la labor creativa propia. En la línea de lo apuntado anteriormente, tomar estas decisiones implica ponderar el valor que se le asigna personalmente al tiempo y al dinero. Se trata de una ecuación que bien puede modificarse en el tiempo, y frente a la cual no todos se encuentran en condiciones equitativas: resulta evidente, por ejemplo, que quienes disponen de recursos económicos previos tienen más libertades para dedicar tiempo a sus labores creativas. La tercera variable, si bien está presente en todas las voces recogidas, pocas veces es suficientemente visibilizada como un trabajo en sí: la gestión. También los creadores culturales deben decidir cuánta energía están dispuestos a inyectar a la gestión de sí mismos: a la construcción de su visibilidad pública; a administrar la frontera entre el trabajo y la vida; a regular la carga emocional de sus actividades productivas; y largo etcétera que nos enfrenta a un dilema basal de los productores culturales: ¿trabajadores o empresarios de sí mismos? 


\section{Ni trabajadores ni empresarios: la creatividad como excepción}

Hemos señalado en las secciones anteriores que el trabajo creativo se ha convertido en un referente significativo para las dinámicas laborales emergentes en diversos sectores productivos. Aunque algunos de sus rasgos se presentan como seductores, nuestros hallazgos de investigación - así como numerosos estudios a nivel internacional- plantean que las condiciones que enfrentan estos campos están lejos de ser envidiables. Los costos subjetivos del trabajo creativo contemporáneo han sido invisibilizados de las discusiones en torno a este modelo laboral: la precariedad en estos campos se expresa de formas variables en el amplio espectro de trabajadores aquí contemplados, pero en todos ellos el estatuto del tiempo, del dinero y de la gestión asumen ciertas tensiones y ambivalencias constitutivas. Dichas tensiones se encuentran íntimamente relacionadas con los modos en que estas actividades productivas se desentienden — niegan, matizan u ocultan — su condición de trabajo. No se trata solamente de una racionalidad capitalista que, tras los destellos de una vida laboral flexible, libre y autónoma, esconda prácticas de explotación de los creadores culturales. En nuestros intentos de aproximarnos a las perspectivas de los actores, hemos podido constatar que buena parte de los trabajadores de la creatividad se enuncian a sí mismos desde discursos de excepción: observamos un esfuerzo importante de parte de estos agentes creativos por situarse fuera de las convenciones sociales y de la condición productiva.

Pero, ¿por qué el hacer artístico se resiste a ser definido, simplemente, como un trabajo? Tomemos como ejemplo el campo de las artes visuales, donde estos discursos se expresan con mayor nitidez. Allí, nuestro estudio pudo observar cómo las voces contemporáneas de los artistas actualizan, de modos diversos, el conjunto de creencias que la sociología del arte ha llamado «régimen de singularidad» ${ }^{10}$, y en el marco de éste, apelan en diversos niveles a la creencia del trabajo artístico como excepción. Esta condición excepcional opera en, al menos, tres claves: en primer término, identificando la excepción artística como una suerte de «excentricidad»; en segundo, distinguiéndola en tanto «privilegio»; y finalmente, como una «carencia» en el marco de las garantías sociales. La primera de ellas - el artista como outsider - tiene una vasta tradición no sólo en Occidente (Heinich, 2002), sino también en otros contextos culturales (Lévi-Strauss, 1971). Como sintetiza Becker en su etnografía de los mundos

10. Hundiendo sus raíces en las representaciones personalistas promovidas por el romanticismo, la identidad artística se configuró históricamente asumiendo que la excelencia estaba dada por la originalidad y la unicidad, las cuales a su vez se materializaban en una capacidad sublime de alcanzar la expresión universal (Heinich, 2002). El artista moderno encarnó, de este modo, el mito del genio creador: un sujeto atípico, solitario y extraordinariamente creativo, que se sitúa en los márgenes del mundo social para iluminarle irreverentemente con sus obras maestras. 
del arte, "el mito romántico del artista sugiere que las personas que tienen ese talento no pueden estar sujetas a las limitaciones que se imponen a los otros miembros de la sociedad: tenemos que permitirles violar reglas de decoro, corrección y sentido común que todos los demás deben respetar a riesgo de ser castigados. El mito sugiere que, a cambio, la sociedad recibe un trabajo extraordinario y muy valioso" (Becker, 2008, p. 32). Esta identificación con la figura del artista como sujeto excéntrico aparece en las voces de diversos creadores de la escena local, sin distinciones de género ni de edad.

"Los artistas somos niños que sobrevivimos. Si un niño hace lo que le gusta y le dices que no lo haga, lo va a hacer igual. [... Los artistas se siguen tirando al piso y están a salvo de las opiniones ajenas ya que se les justifica por ser artistas" (A-M-T1).

Nuestros informantes perciben libertades particulares a la hora de vestirse, de opinar, de rebelarse frente a las imposiciones o de estructurar los tiempos y lugares de trabajo; así como también se sienten ajenos y desconectados respecto de diversas prácticas que son frecuentes para el "común de los mortales". Todo ello, continúa la artista anteriormente citada, "nos brinda sanidad mental, justamente porque no nos reprimimos respecto de las cosas que nos dan placer y disfrutamos de lo que para otros es excentricidad. Logramos conjugar ese universo de juego con el mundo adulto y las responsabilidades" (A-M-T1).

Desde la otra vereda, algunos de los artistas que participaron de nuestra investigación observan el trabajo artístico como una condición minoritaria. "No creo en la idea del artista en tanto ser excepcional dentro de la sociedad que puede dictar qué es la verdad - señala otra artista entrevistada-. En lugar de autoproclamarse una visión privilegiada, me parece que más bien dedicarse al arte es un privilegio" (A-M-T1). Aunque las matrículas universitarias en arte han aumentado en las últimas décadas, todavía la decisión de estudiar una carrera artística es percibida como una posibilidad socialmente restringida, puesto que quienes ingresan a ella son, en definitiva, quienes pueden priorizar la propia vocación antes que la obtención de un medio de subsistencia. Del mismo modo, no todos los que cursan estudios en arte llegan a ser, efectivamente, artistas: en el camino se imponen numerosos filtros, la mayor parte de ellos referidos a las condiciones materiales. Y es que los circuitos artísticos de la escena local no son un asunto de masas: "el arte y el coleccionismo están estrechamente vinculados a las clases sociales en Chile" (A-M-T1), concluye la misma artista. Conscientes de que el límite entre el goce y el trabajo es difuso, los artistas disfrutan ampliamente los privilegios que acompañan su estilo de vida. "Normalmente un descanso para alguien podría ser tomar clases de arte cuando, en realidad, yo trabajo en eso" (A-M-T2), señala una artista de mediana trayectoria. "Uno habla de sus instrumentos de trabajo cuando, en realidad, son juguetes" (A-M-T1), dice, en la 
misma línea, una pintora joven. Esta presencia del disfrute en la vida laboral cobra aún mayor valor por el hecho de ser exclusiva; posible sólo para unos pocos que se sitúan "fuera" del sistema. En ocasiones, incluso, la reflexión que los artistas realizan sobre sus propios privilegios y excepciones contribuye a consolidar un imaginario en el que arte y trabajo resultan excluyentes:

"Hay que hacerse cargo cuando tu vida es infinita e injustamente mejor que las de otras personas Si dices: «Estuve trabajando 8 horas en el taller al igual que tú que estuviste trabajando en la construcción», me parece una falta de respeto. Ambos trabajaron 8 horas, si quieres llamarlo así, pero no es lo mismo. Esta persona se sacó la mierda por un sueldo horrible y tiene la espalda destrozada mientras tú estuviste dibujando o pintando" (A-H-T2).

Pero los artistas bien saben que estos distendidos modos de trabajo traen consigo numerosas dificultades. Como ya hemos observado, la singularidad del régimen artístico también se materializa, a menudo, en una condición de persona singular frente a la contingencia, operando de modo individual y desprovisto de toda garantía de seguridad social. Así como no conocen las vacaciones ni los feriados, muchos artistas tampoco poseen contratos indefinidos, cotizaciones previsionales para la vejez o cobertura de salud. La excepción se experimenta, en este sentido, como una carencia, y resulta preciso que los creadores desplieguen estrategias informales -individuales y colaborativas - para enfrentar la desprotección social. La caracterización de las condiciones laborales de los sectores creativos que hemos realizado en este artículo documenta esta intemperie social, en la que la condición excepcional se traduce en una forma de exclusión respecto de los beneficios sociales de los trabajadores.

Aunque la escena de las artes visuales constituye la disciplina creativa donde estas ideas se expresan de manera más pronunciada, nuestros informantes de los distintos campos de la muestra tienden a suscribir estas creencias para, al menos, una parte de su actividad laboral: el trabajo experimentado como propio. Como ya hemos señalado, esta fracción de sus ocupaciones infunde a su identidad laboral de un sentido que trasciende las fronteras del trabajo, no sólo en tanto permite una percepción de libertad y de expresión de sí, sino también porque les permite conectar con una dimensión humana e inalienable de su práctica. Retomando algunas resonancias de la autonomía artística como régimen moderno de la creatividad, estas labores aquí clasificadas como trabajo propio entroncan con los procesos de individualización del mundo contemporáneo. Retomando los postulados de Kunst (2015), que exponían la matriz común entre las prácticas artísticas y el capitalismo flexible, estas prácticas singulares nos ayudan a comprender el papel de la experimentación con la subjetividad tanto en un dominio como en el otro. Así como el capitalismo ha sido definido no sólo como un modo de producción, sino como una máquina de subjetivación (Lazzaratto, 2006), el 'trabajo experimentado como propio' de los sectores creativos 
ocupa un doble rol en la estructuración de las identidades de quienes lo desempeñan: es un modo de hacer, que a la vez habilita un modo de pensarse en el mundo. Es cierto que con ello se funde, como avizoramos en las secciones iniciales, la distinción que Deleuze y Guattari (2002) hicieran entre el sujeto de enunciado (el capitalista) y el sujeto de enunciación (el proletario). Sin embargo, las numerosas resistencias que encontramos respecto de nombrarse o conceptualizarse desde los lenguajes del autoemprendimiento neoliberal, nos llevan a pensar los límites que estas retóricas contemporáneas encuentran en un contexto creativo como el de Santiago de Chile.

Por una parte, en los distintos campos creativos, predomina una visión realista que enfatiza la precariedad del sector: a diferencia de otras escenas metropolitanas, no habría mucho que disputar en una escena cultural como la santiaguina. Es por ello que esta identidad laboral ambivalente (trabajador y empresario de sí mismo) está siempre siendo puesta a raya, reduciendo las incursiones en el segundo término a comentarios irónicos, simulacros, o usos abiertamente instrumentales de estos vocablos. Así, por ejemplo, las "inversiones" realizadas en sí mismos casi siempre son en tiempo, en materiales e incluso en recursos para la sobrevivencia. Esta generalizada consciencia de la fragilidad de la escena creativa local compele a los artistas y productores culturales a un ajuste permanente de expectativas, y a una cierta liviandad a la hora de referir a la relevancia y las proyecciones de la propia obra.

Por otro lado, siendo Chile un país reconocido como laboratorio del neoliberalismo y en el que - a partir de la dictadura de Pinochet- todos los derechos sociales han sido privatizados, la sobreexigida condición del trabajo creativo toma la forma de un equilibrismo sin malla de contención. Así, en un lugar sin garantías sociales, es preciso poner en su lugar las reales condiciones en las que puede desplegarse este ímpetu emprendedor. Primero, apuntando la nítida diferencia que existe entre quienes cuentan con apoyos financieros familiares o de origen, y quienes no; y segundo, reparando en la creciente importancia que han tenido las iniciativas solidarias y colaborativas, que han movilizado un tipo de agencia - la colectiva - que ha sido invisibilizada en la historia de la creatividad (Mould, 2018), y han puesto en escena formas de resistencia que se enfrentan a la dicotomía con la que suele representarse a los creadores culturales: o sujetos modelos del capitalismo o víctimas de la precariedad (De Peuter y Cohen, 2015).

Así matizado, el parentesco entre ethos creativo y subjetividad capitalista en el contexto local nos enfrenta a un modo de vida laboral que se aferra a una porción -la mayor parte de las veces, muy pequeña- de la práctica de los artistas. La potencia de ese trabajo experimentado como propio tiene tal peso en las identidades profesionales de los creadores culturales que éstos invierten una gran cantidad de energía en blindarlo de otras ocupaciones: mientras esa fracción de la labor se encuentre a salvo, aun cuando tengan que vender su fuerza productiva en la mayor parte de su tiempo, los agentes creativos no se representan a sí mismos ni como trabajadores ni como empresarios. 


\section{Conclusiones}

Las expresiones del trabajo creativo que hemos abordado en este artículo son ciertamente múltiples y diversas, pero en todas ellas podemos distinguir un núcleo de actividades capaces de condensar intensos significados e infundir de sentido a toda la identidad laboral de los creadores culturales. Hemos nombrado este núcleo como el "trabajo experimentado como propio", ya que la dimensión central de éste es cómo los sujetos lo experimentan en términos subjetivos: puede ser una fracción pequeña de sus actividades laborales, o una tarea que ante los ojos de otros no revista particular interés, pero hay algo en esta ocupación que les permite identificarse positivamente con él. Un modo personal de hacer las cosas; quizás una marca que sólo adquiere sentido al ser leída a la luz de toda la carrera creativa, que hace posible conectar con una dimensión trascendente del trabajo por la que vale la pena "dejar la propia humanidad" en ello.

Esta cualidad del trabajo creativo encierra algunas ambivalencias que se activan en el contexto contemporáneo: por un lado, observamos la fácil asimilación de este ethos laboral a las lógicas del capitalismo flexible, en tanto ambos trabajan en el plano de una subjetividad expansiva que se resiste a demarcar el lugar del trabajo; por el otro, hallamos la dificultad de identificar una labor de esta naturaleza con el dominio del trabajo, negando su condición de actividad laboral. Así, los sectores creativos, aunque se valen de la gestión autónoma de la propia fuerza productiva, no se representan ni como sus propios jefes ni como sus únicos empleados. Sólo hacen uso de los conceptos asociados a estos imaginarios - emprendedores/trabajadores - de una forma instrumental, ya sea para obtener réditos económicos puntuales (por ejemplo, postular a un fondo) o para defender gremialmente sus derechos laborales.

Nuestro trabajo de campo permite perfilar las condiciones laborales en las que se desempeña este sector productivo, identificando los costos subjetivos específicos que este vienen asociados con este modo de vida. En este examen, pudimos observar que el trabajo creativo supone una relación conflictiva con el tiempo, con los recursos económicos y con la labor de (auto)gestión, lo cual redunda en una permanente sobrecarga de trabajo y en una compleja mediación de los estados emocionales directamente comprometidos en la labor creativa. En este marco, pudimos identificar tanto tácticas cotidianas como estrategias a largo plazo que permiten a los productores culturales desenvolverse en un medio marcado por la precariedad y la incertidumbre, restituyendo en el análisis la dimensión de la agencia de los sujetos. Nos parece que estas evidencias ofrecen un contrapunto relevante a la expansión de las dinámicas creativas hacia otros ámbitos laborales, y a las celebraciones a la flexibilidad que vienen junto a las transformaciones neoliberales del trabajo. La labor creativa parece conectarnos con una forma de vida que devuelve al trabajo su sentido humano, ofreciendo al sujeto un lugar singular en el engranaje productivo. Nos enfrenta a lo impre- 
decible; lo que se resiste a la estandarización; lo que no puede dosificarse en jornadas perfectamente demarcadas. Pero es precisamente en aquella dimensión libre, viva y gozosa del trabajo creativo donde descansan sus mayores encantos y sus más temibles peligros: porque a la vez que se nos presenta como una práctica emancipada, niega toda inscripción en aquella categoría de la que busca liberarse: el trabajo.

\section{Referencias}

Appadurai, Arjun (2001). La modernidad desbordada. Dimensiones culturales de la globalización. Buenos Aires: Fondo de Cultura Económica.

Blanco, Mercedes (2012). Autoetnografía. Una forma de generación de conocimiento. Andamios, 9(19): 49-74. Recuperado de http://www.scielo.org.mx/pdf/anda/ v9n19/v9n19a4.pdf.

Becker, Howard (2008). Los mundos del arte. Sociología del trabajo artístico. Buenos Aires: Universidad Nacional de Quilmes Editorial.

Berardi, Franco (2003). La fábrica de la infelicidad. Nuevas formas de trabajo y movimiento global. Madrid: Traficantes de sueños.

Bille, Trine (2010). Cool, funky and creative? The creative class and preferences for leisure and culture. International Journal of Cultural Policy. 16(4): 466-496. doi: 10.1080/10286630903302741.

Boltanski, Luc y Ève Chiapello (2002). El nuevo espíritu del capitalismo. Madrid: Akal.

Bonilla, Luis (2018). Barrio Italia en perspectiva: urbanización neoliberal, gentrificación y tendencias segregadoras. Revista CIS, 15(24): 79-95. Recuperado de https://revistacis.techo.org/index.php/Journal/article/view/135/136.

Bourdieu, Pierre (2016). La distinción. Barcelona: Taurus.

Castel, Robert (1997). La metamorfosis de la Cuestión Social. Una crónica del salariado. Buenos Aires: Paidós.

Castel, Robert (2004). La inseguridad. ¿Qué es estar protegido?. Buenos Aires: Manantial.

Corsani, Antonella (2000). Vers un renouveau de l'économie politique. Multitudes. Revue politique, artistique, philosophique, (2). Recuperado de http://www.multitudes.net/Vers-un-renouveau-de-l-economie/.

Currey, Mason (2014). Rituales cotidianos. Cómo trabajan los artistas. Madrid: Turner.

De Certeau, Michel (1996). La invención de lo cotidiano 1, Artes de hacer. México D.F.: Instituto Tecnológico y de Estudios Superiores de Occidente y Universidad Iberoamericana. 
De la Garza, Enrique (2005). Introducción: Del concepto ampliado de trabajo al de sujeto laboral ampliado. En E. de la Garza (comp.), Sindicatos y nuevos movimientos sociales en América Latina (pp. 9-17). Buenos Aires: CLACSO. Recuperado de http://bibliotecavirtual.clacso.org.ar/ar/libros/grupos/sindi/intro.pdf.

De Mattos, Carlos (1992). Modernización neocapitalista y reestructuración productiva y territorial en Chile, 1973-1990. Revista EURE, Revista Latinoamericana de Estudios Urbano Regionales, 18(54): 15-30. Recuperado de https://www.eure.cl/ index.php/eure/article/view/1052.

De Nicola, Alberto, Carlo Vercellone y Giggi Roggero (2007). Contra la clase creativa (Marcelo Expósito, trad.). Transversal. Recuperado de https://transversal.at/ transversal/0207/vercellone/es.

De Peuter, Greig y Nicole Cohen (2015). Emerging labour politics in creativeindustries. En K. Oakley y J, O'Connor (eds.), The Routledge companion to the cultural industries (pp. 305-319). Abingdon: Routledge.

Deleuze, G. y Félix Guattari (2002). Mil Mesetas. Capitalismo y esquizofrenia. Valencia: Pre-Textos.

Durán, María (2010). Bienestar psicológico: el estrés y la calidad de vida en el contexto laboral. Revista nacional de administración, 1(1): 71-84.

Ellis, Carolyn y Arthur Bochner (2000). Autoethnography, Personal Narrative, Reflexivity. Researcher as Subject. En N. Denzin y Y. Lincoln (eds.), Handbook of Qualitative Research (pp. 733-768). California: Sage.

Florida, Richard (2000). The rise of the Creative Class and how it's transforming work, leisure, community, E everyday life. New York: Basic Books.

García Canclini, Néstor (2010). La sociedad sin relato. Antropología y estética de la inminencia. Buenos Aires: Katz.

García Canclini, Néstor, Maritza Urteaga y Francisco Cruces (coords.) (2012). Jóvenes, culturas urbanas y redes digitales. Barcelona: Editorial Ariel y Fundación Telefónica.

Gerber, Verónica, y Carla Pinochet (2012). La era de la colaboración. Mapa abreviado de nuevas estrategias artísticas. En N. García Canclini, F. Cruz, M. Urteaga (coords.), Jóvenes culturas urbanas y redes digitales (pp. 46-63). Madrid: Editorial Ariel y Fundación Telefónica.

Gielen, Anne (2009). Working hours flexibility and older workers' labor supply. Economic Papers, 61(2): 240-274. doi: 10.1093/oep/gpn035.

Girard, Bernard (2009). El modelo Google. Una revolución del management. Barcelona: Verticales de Bolsillo. 
Groys, Boris (2014). Volverse público. Las transformaciones del arte en el ágora contemporánea. Buenos Aires: Caja Negra.

Guadarrama, Rocío (2014). Multiactividad e intermitencia en el empleo artístico: El caso de los músicos de concierto en México. Revista Mexicana de Sociología, 76(1): 7-36. doi: 10.22201/iis.01882503p.2014.1.43671.

Guadarrama, Rocío, Alfredo Hualde y Silvia López (2012). Precariedad laboral y heterogeneidad ocupacional: una propuesta teórico-metodológica. Revista mexicana de sociología, 74(2): 213-243. Recuperado de http://www.scielo.org.mx/scielo. php?script=sci_arttext\&pid=S0188-25032012000200002.

Heinich, Nathalie (2002). La sociología del arte. Buenos Aires: Nueva Visión.

Kim, Jae Yun, Troy Campbell, Steven Shepherd \& Aaron Kay (2019). Understanding contemporary forms of exploitation: Attributions of passion serve to legitimize the poor treatment of workers. Journal of personality and social psychology, 118(1): 121-148. doi: 10.1037/pspi0000190.

Kunst, Bojana (2015). Artist at Work, Proximity of Art and Capitalism. Winchester: Zero Books.

Lazzarato, Maurizio (2006). La máquina (Marcelo Expósito, trad.). Transversal. Recuperado de https://transversal.at/transversal/1106/lazzarato/es\#_ftn2.

Lazzarato, Maurizio (2007). Las desdichas de la "crítica artista" y del empleo cultural (Marcelo Expósito, trad.). Transversal. Recuperado de https://transversal.at/ transversal/0207/lazzarato/es.

Lévi-Strauss, Claude (1971). Introducción a la obra de M. Mauss. En M. Mauss, Sociología y antropología (pp. 13-42). Madrid: Tecnos.

Lorey, Isabell (2006). Gubernamentalidad y precarización de sí. Brumaria, Arte, Máquinas, Trabajo inmaterial, (7): 232-249.

McGee, Micki (2005). Self-help, Inc.: Makeover culture in American life. New York: Oxford University Press. doi: 10.1093/ acprof:oso/9780195171242.001.0001.

Mc Robbie, Angela (2007). La 'losangelización' de Londres: tres breves olas de microeconomía juvenil de la cultura y la creatividad en Gran Bretaña. Transversal. Recuperado de http://eipcp.net/transversal/0207/mcrobbie/es.

Mc Robbie, Angela (2010). Industria Cultural. En A. Machado et al., Ideas recibidas: un vocabulario para la cultura artística contemporánea (pp. 154-170). Barcelona: MACBA.

Moulier Boutang, Yann (2007). Le Capitalisme cognitif: la nouvelle grande transformation. Paris: Editions Amsterdam. New Economy Encyclopedia (1997). 
Mauro, Karina (2018). Entre el mundo del arte y el mundo del trabajo. Herramientas conceptuales para comprender la dimensión laboral del trabajo artístico. Telondefondo, Revista De Teoría Y Crítica Teatral, 14(27): 114-143. doi: 10.34096/tdf. n27.5097.

Mitrovic, Mijail (2020). Miguel Aguirre, Iosu Aramburu y la profesionalización del arte contemporáneo en Lima (1997-2018). Revista Antropologías del Sur, (7): 103131. doi: 10.25074/rantros.v7i13.1724.

Mould, Oli (2018). Against Creativity. Londres: Verso.

New Economy Encyclopedia (1997). Recuperado de www.wired.com.

Nippert-Eng, Christena (1996). Home and work. Chicago: The University of Chicago Press.

Oakley, Kate (2014). Goodwork? Rethinking cultural entrepreneurship. En C. Bilton, y S. Cummings (eds.), Handbook of Management and Creativity (pp. 145-160). Cheltenham: Edward Elgar.

Oliva, Jesús (2017). El trabajo cultural: estudio local sobre las condiciones laborales en tres subsectores culturales. Perspectivas de la Comunicación, 10(2): 143-170. Recuperado de http://revistas.ufro.cl/ojs/index.php/perspectivas/article/view/824.

Oliva, Jesús, Andoni Iso y Ricardo Feliu (2012). Trabajo fluido y ciudad desigual: Los patios traseros de las economías creativas y del conocimiento. Sociología del Trabajo, (75): 53-72. Recuperado de https://recyt.fecyt.es/index.php/sociologiatrabajo/article/view/55369.

Ossa, Carlos (2016). El ego explotado. Capitalismo cognitivo y precarización de la creatividad. Santiago: Ediciones Facultad de Artes, U. de Chile.

Overell, Stephen (2008). Inwardness: The Rise of Meaningful Work». Provocation Series, 4:2. London: The Work Foundation.

Pinochet Cobos, Carla (2020). Antropologías del arte en tiempo presente. Una aproximación desde sus nudos problemáticos. Antropologías del Sur, 7(13): 63-78. doi: 10.25074/rantros.v7i13.1729.

Quiña, Guillermo (2018). Culturepreneurship y condiciones del trabajo en las industrias creativas: Una aproximación a partir del caso de la música independiente. Revista Latinoamericana de Estudios del Trabajo, 22(37): 197-220.

Raunig, Gerald (2007). The Monster Precariat. Transversal. Recuperado de http:// translate.eipcp.net/strands/02/raunig-strands02en.html.

Raunig, Gerald, Gene Ray y Ulf Wuggenig (eds.) (2011). Critique of Creativity: Precarity, Subjectivity and Resistance in the 'Creative Industries'. Londres: MayFlyBooks.

Rifkin, Jeremy (1997). El fin del trabajo. Nuevas tecnologías contra puestos de trabajo: el nacimiento de una nueva era. Barcelona: Paidós. 
Rojek, Chris (2005). Leisure Theory: Principles and Practices. Nueva York: Palgrave Macmillan.

Rosler, Martha (2017). Clase Cultural. Arte y gentrificación. Buenos Aires: Caja Negra Editora.

Ross, Andrew (2009). Nice work if you can get it: Life and labor in precarious times. New York: NYU Press.

Rowan, Jaron (2010). Emprendizajes en cultura. Discursos, instituciones y contradicciones de la empresarialidad cultural. Madrid: Traficantes de Sueños.

Sánchez, Celso (2016). Tiempos de creatividad: El tema de nuestro tiempo. Estudios Filosóficos, 65(189): 255-273.

Schlack, Elke y Neil Turnbull (2011). Capitalizando lugares auténticos. Artistas y emprendimientos en la regeneración urbana. ARQ, (79): 28-42. doi:10.4067/S071769962011000300005.

Sennett, Richard (2001). La corrosión del carácter. Barcelona: Anagrama.

Sinigaglia, Jérémy (2013). Happiness as a Reward for Artistic Work: A Social Norm, from Injunction to Incorporation. Sociétés contemporaines, 91(3): 17-42. doi:10.3917/soco.091.0017.

Sinigaglia-Amadio, Sabrina \& Jerémy Sinigaglia (2015). Tempo de la vie d'artiste : genre et concurrence des temps professionnels et domestiques. Cahiers $d u$ Genre, 59(2): 195-215. doi:10.3917/cdge.059.0195.

Strauss, Anselm y Juliet Corbin (2002). Bases de la investigación cualitativa. Técnicas y procedimientos para desarrollar la teoría fundamentada. Antioquía: Editorial U. de Antioquía.

Tokumitsu, Miya (2015). Do what you love. NuevaYork: Regan Arts.

Tsianos, Vassilis y Dimitris Papadopoulos (2006). Precarity: A Savage Journey to the Heart of Embodied Capitalism. Transversal. Recuperado de https://transversal.at/ transversal/1106/tsianos-papadopoulos/en.

Valenzuela, Hugo, Luis Reygadas y Francisco Cruces (2015). Mi trabajo es mi vida. La incrustación de los mundos de la vida y del trabajo en empresas españolas. REIS. Revista Española de Investigación social, (150): 191- 210. doi: 10.5477/cis/ reis.150.191.

Van Holm, Eric (2014). Leisure choices of the creative class. Cities, 41:38-43. doi: 10.1016/j.cities.2014.05.006.

Virno, Paolo (2008). Gramática de la multitud. Buenos Aires: Colihue.

VVAA. (2004). Capitalismo cognitivo, propiedad intelectual y creación colectiva. Madrid: Traficantes de Sueños. 
Yáñez, Sonia (2001). La flexibilidad laboral como nuevo eje de la producción y la reproducción. En R. Todaro y S. Yáñez (eds.), El trabajo se transforma (pp. 35-73). Santiago: CEM. Centro de Estudios de la Mujer.

Zafra, Remedios (2017). El entusiasmo. Precariedad y trabajo creativo en la era digital. Barcelona: Anagrama.

Zukin, Sharon (2014 [1982]). Loft living. Culture and Capital in Urban Change. New Jersey: Rutgers University Press.

\section{Sobre las autoras}

Carla Pinochet Cobos es Doctora en Ciencias Antropológicas por la Universidad Autónoma Metropolitana, México. Académica del departamento de Antropología, Universidad Alberto Hurtado. Correo Electrónico: carlaasecas@gmail.com. https://orcid.org/0000-0002-8188-2572

Constanza Tobar Tapia es antropóloga social, Universidad de Chile. Correo Electrónico: constanza.tobar.t@gmail.com. https://orcid.org/0000-0001-7929-5873 


\title{
CUHSO
}

Fundada en 1984, la revista CUHSO es una de las publicaciones periódicas más antiguas en ciencias sociales y humanidades del sur de Chile. Con una periodicidad semestral, recibe todo el año trabajos inéditos de las distintas disciplinas de las ciencias sociales y las humanidades especializadas en el estudio y comprensión de la diversidad sociocultural, especialmente de las sociedades latinoamericanas y sus tensiones producto de la herencia colonial, la modernidad y la globalización. En este sentido, la revista valora tanto el rigor como la pluralidad teórica, epistemológica y metodológica de los trabajos.

\author{
EDITOR \\ Matthias Gloël \\ COORDINADORA EDITORIAL \\ Claudia Campos Letelier \\ CORRECTOR DE ESTILO Y DISEÑAdoR \\ Ediciones Silsag \\ Traductor, CORRECTOR LENGUA INGLESA \\ Aurora Sambolin Santiago \\ SITIO WEB \\ cuhso.uct.cl \\ E-MAIL \\ cuhso@uct.cl
}

LICENCIA DE ESTE ARTÍCULO

Creative Commons Atribución Compartir Igual 4.0 Internacional 